\title{
Adherence to drug therapy for hypertensive disorders of pregnancy: a cross-sectional survey
}

\author{
Haihong Chen', Yuqing Tang ${ }^{1}$, Chenxi Liu', Junjie Liu², Kang Wang ${ }^{3}$ and Xinping Zhang ${ }^{*^{*}}$ (D)
}

\begin{abstract}
Background: Hypertensive disorders of pregnancy (HDPs) are a major contributor to maternal mortality worldwide, and drug therapy for HDPs is complicated and special. Clinical guidelines help physicians optimize the care for HDPs, but little is known about whether physicians adhere to drug therapy guidelins well, especially in China. This study aims to evaluate adherence to the drug therapy guidelines of the Chinese Obstetricians and Gynecologists Association (COGA) for HDPs and to explore the corresponding associations with recommendation evidence.

Methods: A cross-sectional design was executed for 306 women with HDPs hospitalized in a maternity ward of a tertiary hospital from August 2014 to July 2015 in Hubei, China. Adherence to the COGA guidelines was evaluated according to six items: the time of use and route of administration and dosage of antihypertensive drugs, $\mathrm{MgSO}_{4}$, and corticosteroids. Binary logistic regression was adopted to explore the associations between adherence to clinical decisions and recommendation evidence.
\end{abstract}

Results: The average adherence rate for drug therapy for HDPs was $48.22 \%$. The adherence rate for the time of antihypertensive drug and corticosteroid use scored 95.65 and $86.75 \%$, whereas the other four items of the time of $\mathrm{MgSO}_{4}$ use and the routes of administration and dosages of antihypertensive drugs, $\mathrm{MgSO}_{4}$, and corticosteroids scored $<50.00 \%$. High- and low-evidence-based recommendations were followed in 40.00 and $54.70 \%$ of the decisions, respectively. Logistic regression revealed that recommendation evidence ( $O R=0.588, P=0.003$ ) was associated with adherence.

Conclusions: Further improvement is still needed to achieve good adherence, especially regarding the time of $\mathrm{MgSO}_{4}$ use and drug dosage. High-evidence-based management of drug therapy for HDPs should be strengthened.

Keywords: Hypertensive disorders, Pregnancy, Adherence, Drug therapy, Evidence

\footnotetext{
* Correspondence: xpzhang602@hust.edu.cn

${ }^{1}$ School of Medicine and Health Management, Tongji Medical College,

Huazhong University of Science and Technology, No.13. Hangkong Road,

Wuhan 430030, Hubei Province, China

Full list of author information is available at the end of the article
}

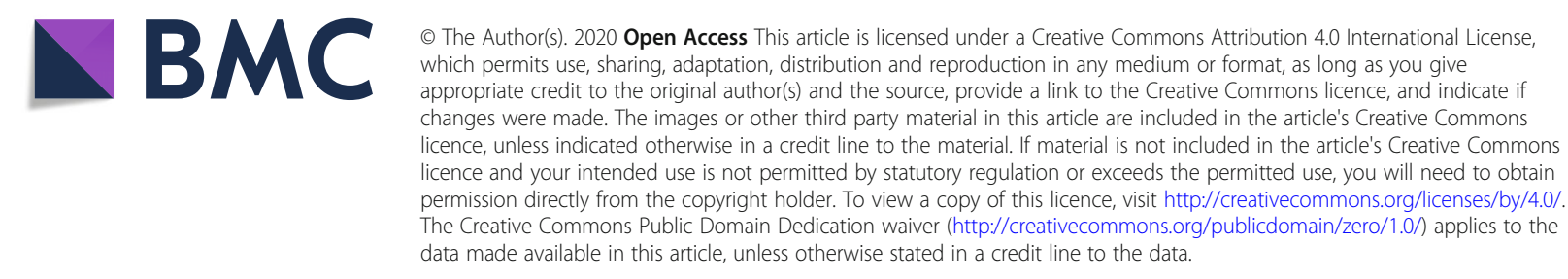




\section{Background}

Hypertensive disorders of pregnancy (HDPs) affect approximately 5 to $10 \%$ of all pregnancies [1]. HDPs include gestational hypertension, chronic hypertension, pre-eclampsia, eclampsia, and chronic hypertension with superimposed pre-eclampsia [1-3]. HDPs are a major contributor to maternal mortality worldwide [4, 5] and are responsible for 16.1 and 9.1 to $25.7 \%$ of maternal deaths in developed and developing countries, respectively [4].

Evidence-based clinical practice guidelines (CPGs) should promote best practices in HDP management to reduce mortality in women with or at risk of developing HDPs, and to reduce infant morbidity and mortality [6]. To help physicians optimize care for HDPs, many national and international evidenced-based CPGs on HDP management, such as the guidelines of the Chinese $\mathrm{Ob}$ stetricians and Gynecologists Association (COGA), Society of Obstetricians and Gynaecologists of Canada (SOGC), and World Health Organization (WHO), have been published [3, 7].

Drug therapy for HDPs is complicated and special because it considers the mother and the foetus. Drug therapy recommendations in guidelines involve a careful balance between risk and benefit, with an overall goal of improving maternal and foetal outcomes [8]. Adherence to these recommendations increases the use of necessary treatment and reduces maternal and perinatal risk $[9,10]$.

Previous studies evaluating drug therapy guideline adherence for HDPs have mainly focused on the time of drug use [11-13], and guideline adherence regarding the route of administration and drug dosage is unknown, especially in China. The associations between drug therapy guideline adherence for HDPs and recommendation evidence are also unclear.

This study aims to evaluate adherence to the COGA drug therapy guidelines for HDPs in terms of time of drug use, route of administration, and drug dosage and to explore the corresponding associations with recommendation evidence in a tertiary hospital in Hubei, China. The findings will improve drug therapy management and guideline implementation for HDPs, especially the implementation of recommendations with high evidence.

\section{Methods}

\section{Design and setting}

A cross-sectional design was used for the study. The study was conducted in the maternity ward of a tertiary hospital in Hubei, China. This tertiary hospital is a university teaching hospital with a 6000 bed facility, attending approximately 17,000 outpatients per day.

\section{Participants and sampling}

The source populations were all women $(n=415)$ with HDPs hospitalized in a maternity ward at this tertiary hospital from August 2014 to July 2015. We excluded 109 women with the following conditions: (1) no specific diagnosis of an HDP or the corresponding classification (gestational hypertension, chronic hypertension, nonsevere or severe pre-eclampsia, eclampsia, or chronic hypertension with superimposed non-severe or severe pre-eclampsia) based on the COGA guidelines [3]; (2) < 28 weeks of gestation; (3) no birth at this tertiary hospital; (4) stillbirth or postpartum bleeding at admission; or (5) incomplete medical records. Finally, 306 women were included in the analysis. Among them, 47 were diagnosed with gestational hypertension, 17 with chronic hypertension, 40 with non-severe pre-eclampsia, 184 with severe pre-eclampsia, and 18 with chronic hypertension with superimposed severe pre-eclampsia.

\section{Measurements}

Items of adherence measurement

Six items of drug therapy and nine detailed items of drug dosage were created to evaluate the drug therapy guideline adherence (Table 1), consistent with the recommendations of the COGA guidelines in 2012 [3], on which the clinical decisions of the physicians were based in our study. The translation of these recommendations of the COGA guidelines is presented in Additional file 1. We evaluated the drug therapy guideline adherence for antihypertensive drugs, $\mathrm{MgSO}_{4}$, and corticosteroids-the main drugs used for the management of HDPs. Each item was examined for conditionality; that is, items were considered applicable for women with underlying conditions that would have qualified for given the treatments [14]. For each item, the physicians' treatment behaviour for every woman to whom the items were applicable was considered a clinical decision.

\section{Indicators of adherence measurement}

The primary indicator used for evaluating the adherence to drug therapy was the adherence rate, and secondary indicators were underuse and overuse rates. The adherence rate for each item was calculated as the sum of the number of clinical decisions for the item where the physician adhered to the guidelines divided by the number of clinical decisions for the item. The overall adherence rate for all the items was calculated as the sum of the number of clinical decisions for all items where physicians adhered to the guidelines divided by the number of clinical decisions for all the items. The underuse/overuse rate for each item was calculated as the sum of the number of clinical decisions that physicians treated with the drugs at a dosage that was less/more than that recommended for the item divided by the number of 
Table 1 Definitions of the six items for drug therapy of HDPs and their evidence

\begin{tabular}{|c|c|c|c|}
\hline Items & Definitions of applicable women ${ }^{a}$ & Definitions of adherence & Evidence \\
\hline \multicolumn{4}{|l|}{ Antihypertensive drugs } \\
\hline Q1: Time of antihypertensive drug use & Women with $\mathrm{BP} \geq 160 / 110 \mathrm{mmHg}$ & Use antihypertensive drugs & low \\
\hline Q2: Dosage of antihypertensive drugs ${ }^{\mathrm{b}}$ & $\begin{array}{l}\text { Women with } \mathrm{BP} \geq 160 / 110 \mathrm{mmHg} \\
\text { treated with oral nicardipine } \mathrm{e}^{\mathrm{c}}\end{array}$ & $\begin{array}{l}\text { Adherence to per dose and } \\
\text { dosing frequency }\end{array}$ & low \\
\hline Q2-1 Per dose & & Initial dose $20-40 \mathrm{mg}$ & \\
\hline Q2-2 Dosing frequency & & Three times a day & \\
\hline \multicolumn{4}{|l|}{$\mathrm{MgSO}_{4}$} \\
\hline Q3: Time of $\mathrm{MgSO}_{4}$ use & Women with severe pre-eclampsia & Use $\mathrm{MgSO}_{4}$ & high \\
\hline Q4: Route of administration and dosage of $\mathrm{MgSO}_{4}$ & $\begin{array}{l}\text { Women with severe pre-eclampsia } \\
\text { treated with } \mathrm{MgSO}_{4}\end{array}$ & $\begin{array}{l}\text { Adherence to route, loading } \\
\text { dose, and maintenance dose }\end{array}$ & low \\
\hline Q4-1 Route & & Intravenous or intramuscular & \\
\hline Q4-2 Loading dose & & $2.5-5 \mathrm{~g}$ & \\
\hline Q4-3 Maintenance dose & & Not more than $25 \mathrm{~g}$ in $24 \mathrm{~h}$ & \\
\hline \multicolumn{4}{|l|}{ Corticosteroids } \\
\hline Q5: Time of corticosteroid use & $\begin{array}{l}\text { Women with severe pre-eclampsia, } \\
\text { before } 34 \text { weeks of gestation when } \\
\text { delivery is probable within } 7 \text { days }\end{array}$ & Use corticosteroids & high \\
\hline $\begin{array}{l}\text { Q6: Route of administration and dosage } \\
\text { of corticosteroids } \text { b }^{-}\end{array}$ & \multirow[t]{5}{*}{$\begin{array}{l}\text { Women with pre-eclampsia, before } \\
34 \text { weeks of gestation when delivery } \\
\text { is probable within } 7 \text { days, treated with } \\
\text { dexamethasone }\end{array}$} & $\begin{array}{l}\text { Adherence to route, per dose, } \\
\text { dosing frequency, and continuous } \\
\text { treatment times }\end{array}$ & \multirow[t]{5}{*}{ low } \\
\hline Q6-1 Route & & Intramuscular & \\
\hline Q6-2 Per dose & & $5 \mathrm{mg}$ & \\
\hline Q6-3 Dosing frequency & & Two times a day & \\
\hline Q6-4 Continuous treatment times & & Four times & \\
\hline
\end{tabular}

Notes: HDPs hypertensive disorders of pregnancy. $Q i(i=1$ to 6$)$ is the code for items, and Qi-j $(i=2,4$ or $6 ; j=1,2,3$ or 4$)$ is the code for detailed items of $Q i$ ${ }^{a}$ The applicable and adhering situation of women with chronic hypertension with superimposed pre-eclampsia referred to women with chronic hypertension or pre-eclampsia [3]. ${ }^{\mathrm{b}}$ In the route of administration and dosage of antihypertensive drugs and corticosteroids, the most frequently used drugs, such as nicardipine and dexamethasone, are presented. ${ }^{c}$ Data on the dosage of intravenous nicardipine were unavailable. Hence, only the dosage of oral nicardipine was evaluated

clinical decisions for this item. Six items of drug therapy and nine detailed items of drug dosage could be calculated by the adherence rate, but underuse and overuse rates could only be calculated for nine detailed items of drug dosage.

\section{Recommendation evidence measurements}

In the COGA guidelines, some recommendations were ascribed with evidence levels I, II-1, II-2, II-3, or III. These evidence levels were defined in accordance with the guidelines of the SOGC [15]. For example, level $I$ indicates that evidence was obtained from at least one properly randomized controlled trial. In this study, we considered level $I$ as high evidence and II-1, II-2, and II3 as moderate evidence. Level $I I I$ and without evidence or references behind recommendations were considered low evidence. The evidence levels for the six items of drug therapy are listed in Table 1 . We found that none of six items was moderate evidence according to Chinese guidelines, so the evidence levels of these items were either high or low.

\section{Data collection}

Data on women's general characteristics (type of HDPs, weeks of gestation at admission, type of delivery, number of foetuses, time from admission to delivery, health insurance, age, parity, and number of abortions), blood pressure with multiple monitoring, and drug therapy from admission to delivery were collected by electronic medical records. The records are represented by International Classification of Diseases, Tenth Revision (ICD 10) codes.

\section{Statistical analysis}

Descriptive statistics included frequencies and proportions for categorical data and median with lower quartile $\left(\mathrm{P}_{25}\right)$ and upper quartile $\left(\mathrm{P}_{75}\right)$ for continuous data. To explore the association between guideline adherence and recommendation evidence, we performed binary logistic regression by using adherence to clinical decisions $(n=647)$ as the dependent variable, and recommendation evidence and general characteristics as the independent variables. Standard error was clustered at the patient level. In the logistic regression, the analytical unit was each item (Q1, Q2, Q3, Q4, Q5 or Q6) that did not include nine detailed 
items for every woman, and the overall number of clinical decisions for 306 women was 647. Each item could be evaluated with whether adhered to, but underuse or overuse could only be applicable to drug dosage which was the details of Q2, Q4 or Q6. Therefore, we did not use underuse or overuse as the dependent variable in the logistic regression. We used the Pearson chi-square goodness-of-fit test to assess the goodness of fit of our model. Odds ratios (ORs) and 95\% confidence intervals (CIs) were calculated. $P<0.05$ was considered statistically significant. Statistical analysis was conducted using STATA 12.0 (STATA Corp, College Station, TX, USA).

\section{Results}

\section{General characteristics of participants}

The characteristics of the 306 women are summarized in Table 2. The majority of the women were diagnosed

Table 2 General characteristics of women with HDPs

\begin{tabular}{|c|c|}
\hline Variable name & $\begin{array}{l}\text { Frequency (percentage)/ } \\
\text { median }\left(P_{25} \sim P_{75}\right)^{a} N=306\end{array}$ \\
\hline \multicolumn{2}{|c|}{ Type of hypertensive disorders of pregnancy, n(\%) } \\
\hline Gestational hypertension & $47(15.36)$ \\
\hline Chronic hypertension & $17(5.56)$ \\
\hline Non-severe pre-eclampsia & $40(13.07)$ \\
\hline Severe pre-eclampsia & $184(60.13)$ \\
\hline $\begin{array}{l}\text { Chronic hypertension superimposed } \\
\text { severe pre-eclampsia }\end{array}$ & $18(5.88)$ \\
\hline \multicolumn{2}{|l|}{ Weeks of gestation at admission, n(\%) } \\
\hline $28 \sim$ & $91(29.74)$ \\
\hline $34 \sim$ & $97(31.70)$ \\
\hline $37 \sim$ & $118(38.56)$ \\
\hline \multicolumn{2}{|l|}{ Type of delivery, n(\%) } \\
\hline Eutocia & $10(3.27)$ \\
\hline Caesarean & $293(95.75)$ \\
\hline Induced labour & $3(0.98)$ \\
\hline \multicolumn{2}{|l|}{ Number of foetuses, n(\%) } \\
\hline Single & $257(83.99)$ \\
\hline Twins & $49(16.01)$ \\
\hline \multicolumn{2}{|l|}{ The time from admission to delivery, $\mathrm{n}(\%)$} \\
\hline$<24 \mathrm{~h}$ & $95(31.05)$ \\
\hline$\geq 24 \mathrm{~h}$ & $211(68.95)$ \\
\hline \multicolumn{2}{|l|}{ Health insurance, $n(\%)$} \\
\hline No & $31(10.13)$ \\
\hline Yes & $275(89.87)$ \\
\hline Age, median $\left(P_{25} \sim P_{75}\right)$ & $30(27 \sim 35)$ \\
\hline Parity, median $\left(P_{25} \sim P_{75}\right)$ & $0(0 \sim 1)$ \\
\hline Number of abortions, median $\left(P_{25} \sim P_{75}\right)$ & $1(0 \sim 2)$ \\
\hline
\end{tabular}

Notes: HDPs hypertensive disorders of pregnancy

${ }^{\text {a }} \mathrm{P}_{25}$ representes the lower quartile, and $\mathrm{P}_{75}$ representes the upper quartile with severe pre-eclampsia (60.13\%), were admitted at $\geq 37$ weeks of gestation (38.56\%), underwent caesarean delivery (95.75\%), carried a single foetus (83.99\%), spent $\geq 24 \mathrm{~h}$ from admission to delivery (68.95\%), and possessed health insurance (89.87\%). The median age, parity, and number of abortions of these women were 30 years, zero, and one, respectively.

\section{Adherence, underuse and overuse rates}

The average adherence rate for drug therapy for HDPs was $48.22 \%$ (312/647), ranging from 0 to $95.65 \%$ for six items. High- and low-evidence-based recommendations were followed in $40.00 \%(114 / 285)$ and $54.70 \%(199 / 362)$ of decisions, respectively.

The adherence rates for antihypertensive drugs, $\mathrm{MgSO}_{4}$, and corticosteroids are presented in Fig. 1. The adherence rates for the time of antihypertensive drug and corticosteroid use were 95.65 and $86.75 \%$, respectively. However, the adherence rate for the time of $\mathrm{MgSO}_{4}$ use scored $20.79 \%$, which was relatively poor. Although the adherence rates for the routes of administration of $\mathrm{MgSO}_{4}$ and corticosteroids were 100 and $90.28 \%$, respectively, adherence to the dosages of antihypertensive drugs, $\mathrm{MgSO}_{4}$, and corticosteroids were relatively poor.

The underuse and overuse rates for these drugs are presented in Figs. 2 and 3, respectively. No women were treated with an inadequate loading dose of $\mathrm{MgSO}_{4}$ or inadequate per dose of antihypertensive drugs or corticosteroids, and $45.98 \%$ were treated with an inadequate dosing frequency of antihypertensive drugs. However, the overuse rate for the loading dose of $\mathrm{MgSO}_{4}$ was $52.38 \%$, and those of the per dose, dosing frequency and continuous treatment times of corticosteroids were 98.61, 11.11 and $18.06 \%$, respectively. Details on the guideline adherence regarding antihypertensive drugs, $\mathrm{MgSO}_{4}$, and corticosteroids are presented in Additional files 2, 3 and 4: Tables S1, S2 and S3.

\section{Association between adherence and recommendation evidence}

The logistic regression analysis results are shown in Table 3. The recommendation evidence $(\mathrm{OR}=0.588$, $P=0.003)$ was significantly associated with guideline adherence.

\section{Discussion}

In this study on drug therapy guideline adherence for HDPs, we found that the average adherence rate for drug therapy for HDPs is not optimistic $(<50 \%)$, especially regarding the time of $\mathrm{MgSO}_{4}$ use and drug dosage. High adherence is negatively associated with high recommendation evidence. 




Fig. 1 Adherence rates for antihypertensive drugs, MgSO4, and corticosteroids. Qi ( $i=1$ to 6$)$ is the code for items, and Qi-j ( $i=2,4$ or $6 ; j=1,2,3$ or 4) is the code for detailed items of Qi. The red, grey and blue rectangles represent the adherence rates for antihypertensive drugs, MgSO4 and corticosteroids, respectively

The adherence rate for time of MgSO4 use was 20.79\%. Similar findings have been previously reported [12, 13]. However, Shields et al. showed that high levels of compliance can be achieved in a relatively short period of time [16]. Thus, active measures, such as providing feedback on the quality of care, drilling and displaying guidelines, and using web-based applications to improve adherence on the time of $\mathrm{MgSO}_{4}$ use must be employed [12, 17].

This study revealed that guideline adherence regarding drug dosage was relatively low. We found that $45.98 \%$ of the women were treated with oral nicardipine fewer than three times a day, and $52.38 \%$ of the women were treated with an overstandard loading dose of $\mathrm{MgSO}_{4}$. These findings highlighted that the dosing frequency of oral nicardipine and loading dose of $\mathrm{MgSO}_{4}$ were overlooked. The overuse of per dose, dosing frequency and continuous treatment times of dexamethasone were serious problems. The use of repeated courses of antenatal corticosteroids was one of the issues [18], and dexamethasone has been overused in many clinical departments, such as emergency [19] and paediatrics [20]. Overusing corticosteroids antenatally does not improve outcomes and is associated with increased mortality, decreased foetal growth, and prolonged adrenal suppression [21].

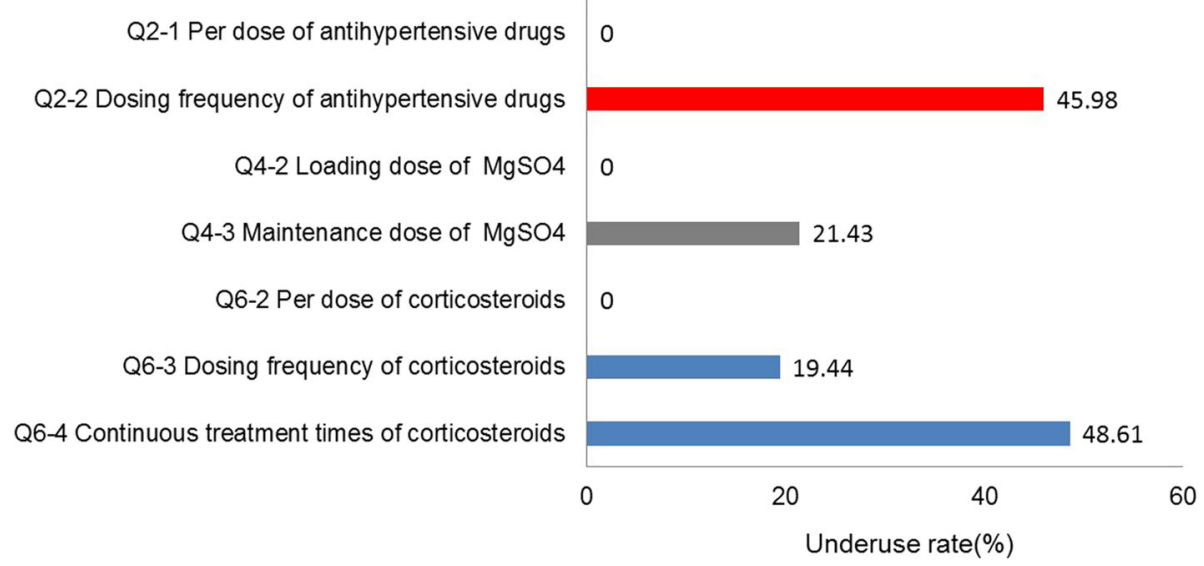

Fig. 2 Underuse rates for antihypertensive drugs, MgSO4, and corticosteroids. Qi-j ( $i=2,4$ or $6 ; j=1,2,3$ or 4 ) is the code for detailed items of dosage of drugs. The red, grey and blue rectangles represent the underuse rates for antihypertensive drugs, MgSO 4 and corticosteroids, respectively 




Notably, the adherence to high evidence-based recommendations was low. Grol et al. found that general practitioners adhered to more evidence-based recommendations than those not based on evidence [22]. This difference was probably associated with different study populations. We mainly focused on obstetricians in a tertiary hospital rather than general practitioners. Although the evidence for the recommendations was essential [22], high evidence was not always associated with high adherence. First, clinical evidence for drug therapy for HDPs was relatively absent in general, and some recommendations were based more on opinion than on

Table 3 Binary regression analysis

\begin{tabular}{|c|c|c|c|c|c|c|}
\hline & \multirow[t]{2}{*}{$z$} & \multirow{2}{*}{$\begin{array}{l}\text { standard } \\
\text { error }\end{array}$} & \multirow[t]{2}{*}{$P$} & \multirow[t]{2}{*}{ OR } & \multicolumn{2}{|l|}{$95 \% \mathrm{Cl}$} \\
\hline & & & & & Lower & Upper \\
\hline \multicolumn{7}{|c|}{ Type of hypertensive disorders of pregnancy } \\
\hline Severe pre-eclampsia & -2.57 & 0.084 & 0.010 & 0.751 & 0.604 & 0.934 \\
\hline Non-severe pre-eclampsia ${ }^{a}$ & - & - & - & - & - & - \\
\hline Chronic hypertension & 1.38 & 1.503 & 0.166 & 2.389 & 0.696 & 8.199 \\
\hline Gestational hypertension & 1.10 & 1.066 & 0.271 & 1.872 & 0.613 & 5.717 \\
\hline \multicolumn{7}{|l|}{ Weeks of gestation at admission } \\
\hline $34 \sim$ & 0.70 & 0.180 & 0.487 & 1.119 & 0.816 & 1.534 \\
\hline $37 \sim$ & 2.20 & 0.188 & 0.028 & 1.357 & 1.033 & 1.781 \\
\hline \multicolumn{7}{|l|}{ Type of delivery } \\
\hline Caesarean & 2.30 & 0.365 & 0.021 & 1.659 & 1.078 & 2.555 \\
\hline Induced labour & 0.48 & 0.414 & 0.635 & 1.181 & 0.595 & 2.346 \\
\hline Number of foetuses & 0.84 & 0.159 & 0.403 & 1.125 & 0.853 & 1.484 \\
\hline Time from admission to delivery & 1.02 & 0.133 & 0.309 & 1.127 & 0.895 & 1.420 \\
\hline Health insurance & -0.81 & 0.142 & 0.418 & 0.877 & 0.639 & 1.204 \\
\hline Age & -0.11 & 0.010 & 0.916 & 0.999 & 0.979 & 1.019 \\
\hline Parity & 0.39 & 0.087 & 0.699 & 1.033 & 0.876 & 1.218 \\
\hline Number of abortions & 0.72 & 0.040 & 0.473 & 1.028 & 0.953 & 1.108 \\
\hline Evidence & -2.94 & 0.106 & 0.003 & 0.588 & 0.412 & 0.838 \\
\hline Constant & -1.28 & 0.221 & 0.201 & 0.646 & 0.331 & 1.262 \\
\hline Goodness-of-fit test ${ }^{b}$ & & & 0.974 & & & \\
\hline
\end{tabular}

Notes: ${ }^{a}$ In the logistic regression, the number of non-severe pre-eclampsia cases was only 2 , so the $\mathrm{z}$ value, standard error, $P$ value, OR and $95 \% \mathrm{Cl}$ were not estimated

b Pearson Chi-Squared goodness-of-fit test 
evidence [23]. For example, antihypertensive treatment was strongly recommended by the WHO for severe hypertension [23]. The adherence rate of this recommendation was high in our study despite low scientific evidence. Second, some high-evidence-based recommendations, especially the time of $\mathrm{MgSO}_{4}$ use, were overlooked in clinical practice. Finally, the clinical conditions were highly complicated, and factors associated with guideline adherence were complex. Abnormal laboratory or physical findings, high operative risk, intolerance for recommended treatment, and extensive comorbidities may influence guideline adherence [24], causing poor adherence of physicians to high-evidence-based recommendations. The sample size for the logistic analysis in our study was 647 (adherence and nonadherence were 312 and 335, respectively), and the overall adherence rate was $48.22 \%$. The number of independent variables was 10 . According to the rule of thumb that logistic models should be used with a minimum of 10 events per variable [25], we estimate that the minimum sample size should be $208(10 * 10 / 48.22 \%)$. Therefore, we thought the sample size might be sufficient for the logistic analysis.

There were some limitations to this study. First, physician factors, such as unfamiliarity with the guidelines [26], lack of guideline awareness [27], and difficulty changing routines and habits [28], may cause low adherence. However, professional factors have not been included as an independent variable in the regression analysis for unavailable data. Second, adherence to guidelines is professional-specific, and different physicians work in different contexts, so our results might not be transferable to other settings. In addition, we excluded women with incomplete medical records which may lead to selection bias.

\section{Conclusions}

Further improvement is still needed to achieve good adherence, especially regarding the time of $\mathrm{MgSO}_{4}$ use and drug dosage. High-evidence-based management for drug therapy for HDPs should be strengthened. Improvement in drug therapy with high-evidence will promote rational use of drugs and reduce maternal and perinatal risk.

\section{Supplementary information}

Supplementary information accompanies this paper at https://doi.org/10. 1186/s13690-020-00423-0.

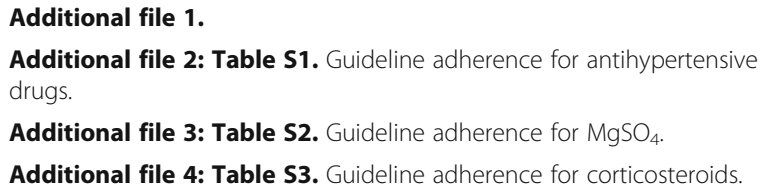

Additional file 2: Table S1. Guideline adherence for antihypertensive drugs.

Additional file 3: Table S2. Guideline adherence for $\mathrm{MgSO}_{4}$. Additional file 4: Table S3. Guideline adherence for corticosteroids.

\section{Abbreviations}

HDPs: Hypertensive disorders of pregnancy; CPGs: Clinical practice guidelines; COGA: Chinese Obstetricians and Gynecologists Association; SOGC: Society of Obstetricians and Gynaecologists of Canada; WHO: World Health Organization; ICD 10: International Classification of Diseases, Tenth Revision; OR: Odds ratios; Cls: Confidence intervals

\section{Acknowledgements}

The authors would like to thank the staff of the tertiary hospital in Hubei for their support of our data collection in the study.

\section{Authors' contributions}

HC contributed to the conception and design, data collection, analysis and interpretation, and manuscript writing and revising. YT contributed to data analysis and interpretation, and revising the manuscript. $\mathrm{CL}, J \mathrm{~L}$ and $\mathrm{XZ}$ contributed to the conception and design, data interpretation and manuscript revising. KW contributed to data collection and interpretation, and revising the manuscript. The author(s) read and approved the final manuscript.

\section{Funding}

This work was supported by the National Natural Science Foundation of China [Grant No. 71473098] and the National Natural Science Foundation of China [Grant No. 71774059].

\section{Availability of data and materials}

The datasets used and/or analysed during the current study are available from the corresponding author on reasonable request.

\section{Ethics approval and consent to participate}

This study was approved by the Research Ethics Committee of Tongji Medical College, Huazhong University of Science and Technology (IORG No: IORG0003571). Consent from women whose records were included was not sought because their private information, such as name and identity card information, was not obtained.

\section{Consent for publication}

Not applicable.

\section{Competing interests}

The authors declare that they have no competing interests.

\section{Author details}

${ }^{1}$ School of Medicine and Health Management, Tongji Medical College, Huazhong University of Science and Technology, No.13. Hangkong Road, Wuhan 430030, Hubei Province, China. ${ }^{2}$ School of Statistics and Mathematics, Central University of Finance and Economics, Beijing, China. ${ }^{3}$ Department of Forensic Medicine, Tongji Medical College, Huazhong University of Science and Technology, Wuhan, Hubei Province, China.

Received: 6 November 2019 Accepted: 23 April 2020

Published online: 08 May 2020

\section{References}

1. Hutcheon JA, Lisonkova S, Joseph KS. Epidemiology of pre-eclampsia and the other hypertensive disorders of pregnancy. Best Pract Res Clin Obstet Gynaecol. 2011;25:391-403.

2. Lowe SA, Brown MA, Dekker GA, et al. Guidelines for the management of hypertensive disorders of pregnancy 2008. Aust N Z J Obstet Gynaecol. 2009:49:242-6.

3. Hypertensive Disorders of Pregnancy Group of Obstetrics and Gynecology Branch of Chinese Medical Association. Guideline of the diagnosis and treatment of hypertensive disorders of pregnancy (2012 edition). Chin J Obstet Emerg. 2012:47:476-80.

4. Khan KS, Wojdyla D, Say L, Gulmezoglu AM, Van Look PFA. WHO analysis of causes of maternal death: a systematic review. Lancet. 2006;367:1066-74.

5. Duley L. The global impact of pre-eclampsia and eclampsia. Semin Perinatol. 2009;33:130-7.

6. Bazzano AN, Green E, Madison A, Barton A, Gillispie V, Bazzano LAL. Assessment of the quality and content of national and international guidelines on hypertensive disorders of pregnancy using the AGREE II instrument. BMJ Open. 2016;6:e9189. 
7. Gillon TER, Pels A, von Dadelszen P, MacDonell K, Magee LA. Hypertensive Disorders of Pregnancy: A Systematic Review of International Clinical Practice Guidelines. PLoS One. 2014;9:e113715.

8. Brown $\mathrm{CM}$, Garovic VD. Drug treatment of hypertension in pregnancy. Drugs. 2014;74:283-96.

9. Luitjes SH, Wouters MG, Franx A, et al. Guideline-based development of quality indicators for hypertensive diseases in pregnancy. Hypertens Pregnancy. 2013;32:20-31.

10. von Dadelszen P, Sawchuck D, McMaster R, et al. The active implementation of pregnancy hypertension guidelines in British Columbia. Obstet Gynecol. 2010;116:659-66.

11. Helou A, Walker S, Stewart K, George J. Management of pregnancies complicated by hypertensive disorders of pregnancy: could we do better? Aust N Z J Obstet Gynaecol. 2017;57:253-9.

12. Lumala A, Sekweyama P, Abaasa A, Lwanga H, Byaruhanga R. Assessment of quality of care among in-patients with postpartum haemorrhage and severe pre-eclampsia at st. Francis Hospital nsambya: a criteria-based audit. BMC Pregnancy Childb. 2017;17:29.

13. Girard P, Quirion A, Bureau Y. SauvéN. Magnesium sulfate for eclampsia prevention: quality of care evaluation in a tertiary Centre in Québec Canada. Obstet Med. 2014;7:71-6.

14. Gupta D, Sharma D, Kannan N, et al. Guideline adherence and outcomes in severe adult traumatic brain injury for the CHIRAG (collaborative head injury and guidelines) study. World Neurosurg. 2016;89:169-79.

15. Magee LA, Pels A, Helewa M, et al. Diagnosis, evaluation, and management of the hypertensive disorders of pregnancy: executive summary. J Obstet Gynaecol Can. 2014;36:416-38.

16. Shields LE, Wiesner S, Klein C, Pelletreau B, Hedriana HL. Early standardized treatment of critical blood pressure elevations is associated with a reduction in eclampsia and severe maternal morbidity. Am J Obstet Gynecol. 2017;216:411-5.

17. Luitjes S, Mesri K, Wouters M, van Tulder M, Hermens R. PP167A process evaluation of an innovative implementation strategy of the Dutch guidelines on hypertensive disorders in pregnancy using a computerized decision support system. Pregnancy Hypertens. 2012;2:329-30.

18. SEA-ORCHID Study Group, Laopaiboon M, Lumbiganon P, et al. Use of evidence-based practices in pregnancy and childbirth: South East Asia Optimising Reproductive and Child Health in Developing Countries project. PLoS One. 2008;3:e2646.

19. Zhao K. Emergency use of dexamethasone phosphate sodium injections: prescription analysis. Evaluation and Analysis of Drug-Use in Hospitals of China; 2011. p. 475-6.

20. Zhang L. Prescription analysis of pediatric outpatient department. Guide China Med. 2016:145-6.

21. Banks BA, Cnaan A, Morgan MA, et al. Multiple courses of antenatal corticosteroids and outcome of premature neonates. Am J Obstet Gynecol. 1999:181:709-17.

22. Grol R, Dalhuijsen J, Thomas S, Veld C, Rutten G, Mokkink H. Attributes of clinical guidelines that influence use of guidelines in general practice: observational study. BMJ. 1998;317:858-61.

23. World Health Organization: WHO recommendations for Prevention and treatment of pre-eclampsia and eclampsia. http://apps.who.int/iris/bitstream/1 0665/44703/1/9789241548335_eng.pdf (2011). Accessed 20 Mar. 2019.

24. Arts DL, Voncken AG, Medlock S, Abu-Hanna A, van Weert HC. Reasons for intentional guideline non-adherence: a systematic review. Int J Med Inform. 2016;89:55-62.

25. Peduzzi P, Concato J, Kemper E, et al. A simulation study of the number of events per variable in logistic regression analysis. J Clin Epidemiol. 1996;49:1373-9.

26. Desalu OO, Onyedum CC, Adeoti AO, et al. Guideline-based COPD management in a resource-limited setting - physicians' understanding, adherence and barriers:a cross-sectional survey of internal and family medicine hospital-based physicians in Nigeria. Prim Care Respir J. 2013;22:79-85.

27. Drawz PE, Miller RT, Singh S, Watts B, Kern E. Impact of a chronic kidney disease registry and provider education on guideline adherence--a cluster randomized controlled trial. BMC Med Inform Decis Mak. 2012;12:62.

28. Lugtenberg M, Burgers JS, Besters CF, Han D, Westert GP. Perceived barriers to guideline adherence: a survey among general practitioners. BMC Fam Pract. 2011;12:98.

\section{Publisher's Note}

Springer Nature remains neutral with regard to jurisdictional claims in published maps and institutional affiliations.

Ready to submit your research? Choose BMC and benefit from:

- fast, convenient online submission

- thorough peer review by experienced researchers in your field

- rapid publication on acceptance

- support for research data, including large and complex data types

- gold Open Access which fosters wider collaboration and increased citations

- maximum visibility for your research: over $100 \mathrm{M}$ website views per year

At BMC, research is always in progress.

Learn more biomedcentral.com/submissions 